\title{
THE FAMILY AS A “GATHERING”: HOW THE LIFE OF AN OBJECT “MAKES” A FAMILY
}

\section{Philippe Noens and Stefan Ramaekers}

\begin{abstract}
Despite the obvious importance of "family" in people's everyday lives, there is little consensus on what family is. Nevertheless, every answer to the question has important (social, political, legal) consequences. In our research we do not set out from a substantial description of what "family" is. We shift from top-down perspectives on what the family is (or should be) according to some description of it, to concrete socio-material practices that actually "make" a family. In taking this sociomaterial stance, we: (a) acknowledge human agency and at the same time place family members not above material objects but among them; (b) use the idea of "script"-ing to visualize the life of particular objects in a particular family; and (c) come to understand "family" as a gathering of some sort, that is, as an event in which people are (actively) gathering and simultaneously being gathered around some-thing. Drawing on a broad ethnographic exploration we conducted, we will show here how a family is "made" when its inhabitants are gathering and being gathered around the life of an object (in our case here, a newspaper) and hence "become" a family.
\end{abstract}

Keywords: the family, childrearing, socio-materiality, script(ing), Latour, Schatzki

Philippe Noens (the corresponding author) is Ph.D. researcher at the Laboratory for Education and Society, Research Group Education, Culture \& Society, University of Leuven, Andreas Vesaliusstraat 2, Leuven, Belgium, B-3000. Phone: (32) 16-32-62-28.

E-mail: philippe.noens@ppw.kuleuven.be

Stefan Ramaekers, Ph.D. is Associate Professor at the Laboratory for Education and Society, Research Group Education, Culture \& Society, University of Leuven, Andreas Vesaliusstraat 2, Leuven, Belgium, B-3000. Phone: (32) 16-32-62-18.

E-mail: stefan.ramaekers@ppw.kuleuven.be 


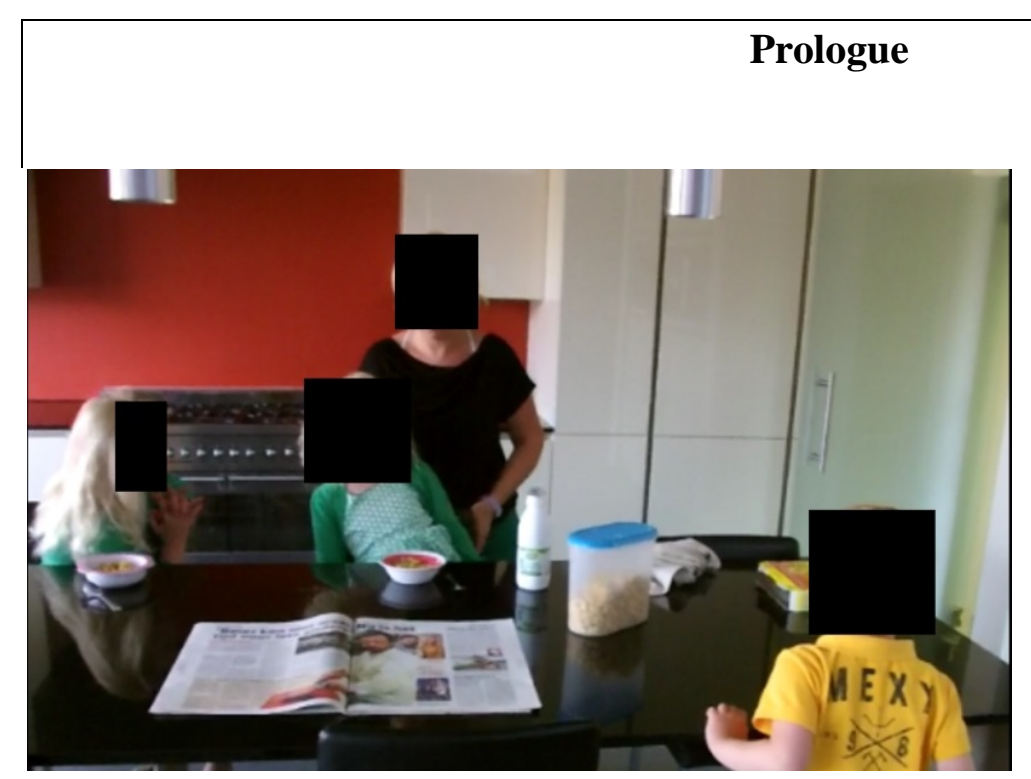

Figure 1. The newspaper at the breakfast table.

\section{[Script]}

Read me if you want to know more about the world. Read me if you want to know more about the past 24 hours, because that's what I'm for. I will inform you. Ignore me. Let me be.

[Researcher's considerations]

The newspaper lies on the kitchen table, pages wide open, inviting those present to read, to jump in a whirl of information - displaying its readability. And yet, nobody does. The newspaper is covering a substantial part of the table, seems to impose itself, stretching itself to the limits of its powers. But mother and her children pay no attention to it at all. Granted, the boy is only three years old and cannot yet read. The same sort of goes for the youngest daughter; she just started learning to read. Nevertheless, the newspaper also features photographs, cartoons and other expressive prints, offering something for everyone ( $a$ children's section is easily found). Moreover, for the moment the newspaper is still a "newpaper", hot off the press. But again: nobody seems to be bothered about it being there. The children just sit opposite or next to it; mother is moving a chair so her daughter can sit straight. Of course, the newspaper is not the only thing on the table. It has to "compete", so to speak, with bowls of cereal, spoons, a bottle of milk, a towel, a box of cereal. Perhaps also, being in a digital world adds to the difficulty for a printed newspaper to be read. But it seems the newspaper does not give up and "stubbornly" continues displaying its readability. 


\section{Introduction: What “makes” a family?}

Throughout history, philosophers, politicians, and the general public have debated what "family" is (not) and should (not) do. Especially during the past half century, a tremendous amount of research has been directed at family-related issues (Weigel, 2008). Studying the contemporary family, questioning the basic concept of "family", is a phenomenon that increasingly gains importance (e.g., Laidlaw, 2006; Newman \& Grauerholz, 2002). This is hardly a surprise. Despite the obvious importance of "family" in people's everyday lives (Thornton \& Young-DeMarco, 2001), there is - for well-known sociological reasons, for example, a multiplicity in family forms - little consensus on what family is. Nevertheless, every answer to the question has important (social, political, legal) consequences. In general, "family" is explained (or "constructed”) from the "outside” (Segrin \& Flora, 2014). Most (sociological) perspectives describe and analyze "family" through (showing the) underlying processes, forces, and (f)actors that are considered to be crucial (and sometimes even essential) criteria in grasping what "family" is all about (e.g., co-residence, the birth of a child, marriage) (e.g., Holtzman, 2008; Koerner \& Fitzpatrick, 2004; Stephens, 1963). To put it differently, in general there is the tendency to explain - or better yet, to "reveal" family - through underlying factors that are then considered to be prime constitutors, hence describing family, in a certain way, as already being "made" (e.g., by social ties; see Morgan, 1996, 2011). The specific "building blocks" involved in this construction are to a large extent already "known" as the "cause" of family (i.e., they are central or essential, the minimum requirement to describe "family"). Instead, we want to describe family as a "practice", that is, as something "in the making". Family, we argue, is a "making" that happens and is made to happen by a group (which we do not define in advance). It refers to the tight "interwovenness" of all sorts of things, since any-thing might potentially connect with anything else and "make" family appear. The term "practice", by pointing to that which is "in the making", thus designates the multiplicity and the complexity of relations and how they appear in their emergence (Mol, 2002). In sum, rather than describe "family" from the "outside", using (mainly) sociological concepts that somehow "construct" family, we want to describe family "in the making", staying close to the process and to the (perhaps unfamiliar or unknown) "building blocks" and hence taking, in a certain way, the idea of "construction" more seriously.

\section{Research Aim}

This study is part of a broader research project (for more information, see https://ppw.kuleuven.be/ecs/les/onderzoek-1/ot20122016). The focus of this broader project is the omnipresence of the language of learning in the theory and practice of education and on how the traditional institutions of "education" (school, university, family) are being affected by the current discourse and practices of "learning". The aim there is to investigate how the current evolution towards learning environments is transforming these "traditional" educational institutions. More particularly what is investigated here is how this evolution affects the kind of "gathering" or "association" that is staged and configured within these sites and especially how this affects their pedagogical character.

In this article, we do not start from a substantial description of what family is; we acknowledge that these "outside" perspectives on what the family is, does (or should be), are useful but, in a certain way, oversimplify things. To be clear, we do not want to ignore, for instance, the particular form a family may take (e.g., Murdock, 1949), the (societal) tasks “family” performs (e.g., Parsons, 1955) or the way people “do” (e.g., Morgan, 1996) or 
experience family (e.g., Bernardes, 1999). Rather, we want to extend these perspectives, arguing that "family" is perhaps more than a setting ("out there"), an experience (of "weness") or an act in itself (a "doing" of some sort). We use the vocabulary of "making" to divert attention from the What (is family) - as an essential core or a minimum requirement, that is, some-thing that is, in a certain way, "in command" of "family" - to the How (is family being forged as a robust alliance with a multitude of still evolving agencies) (Latour, 2005). Indeed, "family" is not only a cognitive sketch resting in the minds of people; it is also a real entity well tied together. In sum, we use the notion of "making" to underline that "family" is not simply and naturally there as the result of some human or social ingenuity, but that "family" is a "construction" of a sea of "things" (and no-thing is a priori the defining creator).

For now, and put in a general way (to be refined later on in this article), it is our intention to articulate the making of a family in terms of descriptions of the interactive relationships between entities. It is a first phase in attempting to understand how, in particular, "things" have the ability to gather people and to understand the kind of gathering that is staged inside the contemporary family. We will clarify our way of thinking by use of a concrete case-study, fully realizing, to be sure that overall conclusions cannot be drawn from it.

\section{A Socio-material Stance}

In line with our research aim we do not start from a substantial or "fixed" description of the family. We want to avoid analyzing what the family "is" (or should be) "top down" and instead try to describe how family takes shape throughout the day - the assumption being that what happens in and as a family cannot solely (or exclusively) be described a priori, but is highly affected by the way "family" is tied together "on the spot" (i.e., on a daily basis, as a "making"). To be precise, linking up to the recent strand of post-humanist philosophies and theories (we will come back to this below), we want to take seriously the idea of the family as a collective or - to use a more theoretical concept - a gathering of different human and nonhuman elements (Latour \& Weibel, 2005). We therefore refrain from approaching family as a collective of humans held together by social roles and/or socio-economic forces. Put differently, the focus is not in first instance on symbolical mediations or inscriptions of relations between family members (e.g., power relations, cultural representations of childhood, the effect of gender on parenting practices). Instead, we want to describe "family" as a collective of humans with and through material things. We elaborate our socio-material stance in three sections: (a) the turn to "things"; (b) the "script" of things; and (c) the family as a gathering around a thing. Later on, the three sections will return as separate parts of the discussion. 


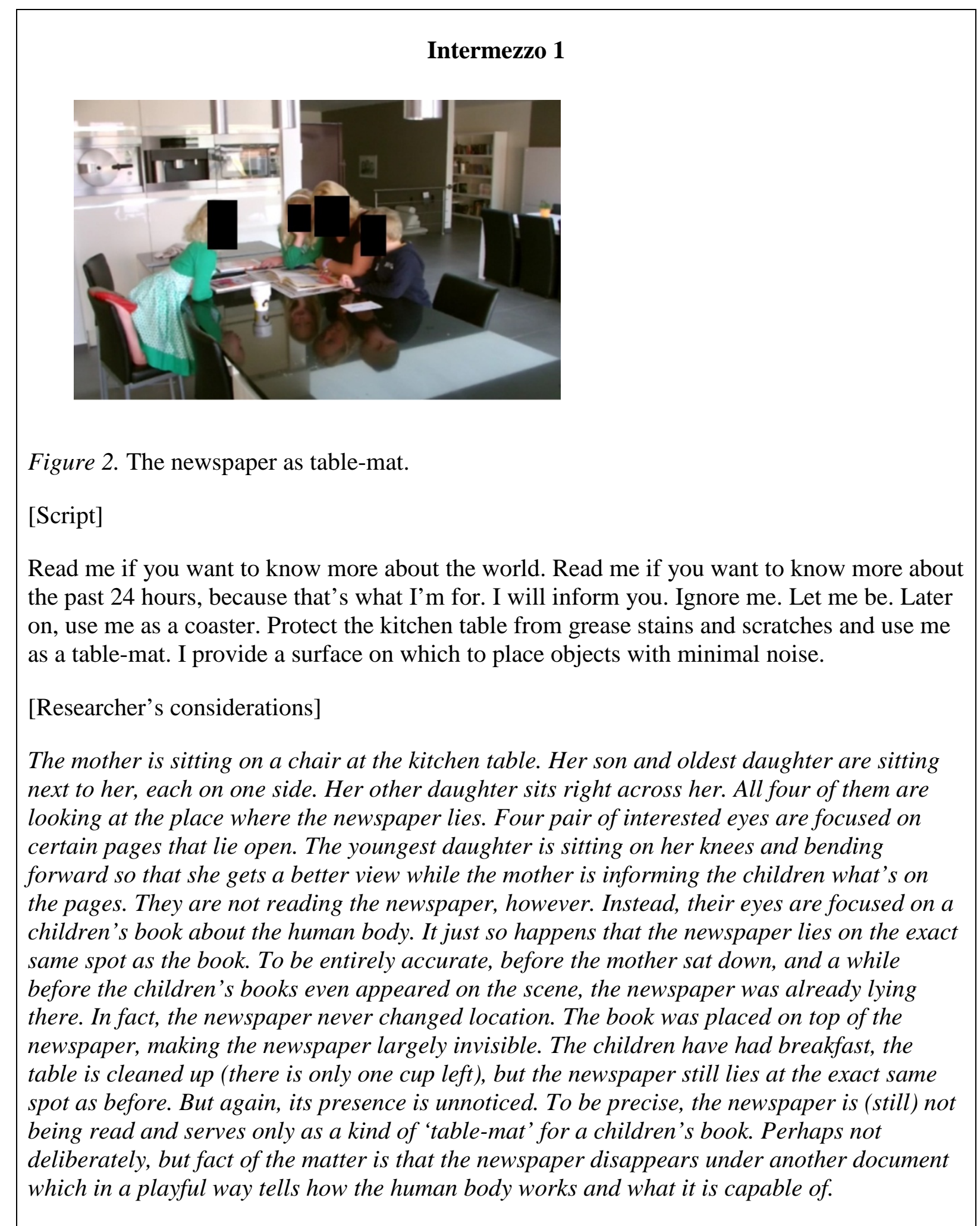


International Journal of Child, Youth, and Family Studies (2014): 5(4.2) 722-740

\section{The turn to "things"}

In a certain way, it is stating the obvious to say that human existence is mixed with materials (since it is hard to imagine our everyday doings without it), but how to deal analytically with the "actions" or effects of things has proved a difficult issue in technology studies (e.g., Pinch, 2010). Indeed, a persistent and well-defended idea in Western thought is that things do not act or perform (outside mechanical causality) and have no "intentions", meanings, goals, or other rational characteristics - intentionality and rationality are typical human characteristics. Therefore, to project agency in entities other than the human subject seems hard to stomach.

Post-humanists such as Latour (1992) and Verbeek (2011) attempt to do away with the predominance of human beings as the sole agents in practices by arguing for a symmetry between humans and non-humans. This symmetry does not mean to imply that things are radically equal to human beings (i.e., that things are of the same importance as human beings) in moral sense, traditionally understood. Rather, the concept proposes to treat humans and non-humans as equivalent on the level of their "doings". In other words, it is acknowledged that humans and non-humans are still different from each other, but the difference no longer is situated in a "traditional" dualism (e.g., subject-object, inside-outside, active-passive) whereby the hierarchy is typically decided in favor of humans. Instead of using a typical oppositional structure, the perspective taken is that humans and non-humans alike attract, repel, collaborate, or transform one another (e.g., Latour, 1992; Verbeek, 2011). The emphasis then comes to lie on an overarching activity, namely network-building, rather than on what this or that entity of a constellation is "by nature". What an entity in a constellation is, or how it should be called, is not something that should be presupposed (e.g., because of a particular type of definition), but is something that is generated in and by the network of relations in which it is situated. Some-thing "is" and takes the shape it does by virtue of the relations it has with other entities in the network.

Be that as it may, attempts such as these to do away with the almost inextricable "agency knot", nevertheless seem to repress another issue, that is, to think about which particular entities (human or non-human) are essential in this or that circumstance and how to make visible their significance. Moreover, even if we accept that humans and non-humans both possess some sort of agency (i.e., agency is distributed over a heterogeneous network of humans and non-humans), we cannot escape the problem that reading agency into things is a human enterprise (e.g., a door is not worried about a wall's "doings" to stand straight). So, some sort of hierarchy or asymmetry seems to be coming in after all. We are prompted to these comments by Schatzki's (2002) version of theory of practice which proposes that what he calls the social site, that is, "the context as part of which human coexistence inherently transpires" (p. 265), is a mesh of practices and orders. Although intimately related - practices maintain and create orders and at the same time orders enable and constrain certain doings and sayings that constitute social practices, thus Schatzki - practices and orders are different in the following relevant aspect: Schatzki sees practices (i.e., an open-ended set of doings and sayings) as an exclusive human enterprise, while orders "are arrangements of entities through and amid which human existence transpires, in which the entities involved relate, occupy positions, and enjoy meaning” (Schatzki, 2002, p. 24). In other words, Schatzki's theory of practice provides an account of the implication of both humans and non-humans (in line with post-humanism) by using the notion of order: an arrangement of (non-)human entities where every-"thing" is active in the constitution of social life. At the same time, Schatzki "preserves" the importance of human agency by containing it to practices. 
In sum, the socio-material stance we make allowances for takes place in a "middle ground". It recognizes that "family" is not solely formed between people but through collective activities between humans and non-humans, between family members and the material world that surrounds them. At the same time, we point out that human doings enjoy primary responsibility for developing, maintaining, or transforming the form family takes.

\section{The script of things}

In "Shaping Technology/Building Society: Studies in Sociotechnical Change” (1992), both Madeleine Akrich and Bruno Latour give extensive consideration to the methodology with which to describe objects; for example: "machines and devices [that] are obviously composite, heterogeneous and physically localized. Although they point to an end, a use for which they have been conceived, they also form part of a long chain of people, products, tools, machines, money, and so forth" (Akrich, 1992, p. 205). Each author however uses a different entry point for describing and analyzing what objects "make" their user do.

Akrich introduces the concept of script as a way to study the relationships between an object's designer (writer) and that object's user (reader) while keeping the materiality of technology (which can be analyzed as a text) in mind. For Akrich (1992), “objects define a framework of action together with the actors and the space in which they are supposed to act" (p. 208). A script, then, is closely related to the intentions of the designers on how the technology should interact with its user(s) and the use context. How the technology can or should be used is, in a sense, "pre-structured": Designers construct an idea of the future user(s) and objectify this idea in the technological design. In other words, designers "inscribe" their representation of the future user in the technology and as a result, technologies "contain" scripts, that is, prescriptions on what the users are supposed to do with the technology at hand. At the same time, Akrich (1992) leaves room for the user as an active "troublemaker", going beyond the inscriptions of designers or adopting new user roles. Nevertheless, it seems that Akrich (1992) gives more relevance to the human beings (designer, user) surrounding the objects than to the objects themselves.

Latour (1992), on the other hand, focuses more closely on the objects themselves. He distinguishes between what he calls "the programs of action" and scripts. A program of action, for Latour, is "the set of written instructions that can be substituted by the analyst to any artifact” (Latour, 1992, p. 175). For instance, the program of action of the seat belt sensor and accompanying alarm is the following: "if a car is moving, then the driver has a seat belt on" (Latour, 1992, p. 152). Therefore, a program of action reflects a network of both human and non-human elements like the driver, the car, the seat belt, the red light "fasten your seat belt" and the alarm. A script, for Latour, is "shorter", more object-oriented, and can be compared to the "script" of a movie. As in a movie script where the sentences prescribe what someone does and when, Latour holds that an object can "prescribe" what someone does and when. For instance, the script of the speed bump is "slow down", forcing a driver to hit the brakes. Latour (1992) acknowledges that designers inscribe a certain program of action, but such a program of action is deployed by the object itself through its very shape. It is this script (i.e., the possibility that an object takes hold of a passer-by and forces her to act or to perform something) that Latour (1992) takes into consideration. In this way, the script is a possibility since it does not fully determine the user's actions. 
In sum, whereas Akrich (1992) links the script more with the intentions and assumptions of designers, Latour (1992) focuses on the potential of the object itself. But the bottom line is the same: Both subscribe to the idea that the concept of script shows how artifacts can shape, or at least influence, human action and behavior.

This idea of script seems a very useful conceptual tool to understand how "things" make a family and how things manage to gather a "family" around them, not in the least because both Akrich (1992) and Latour (1992) also provide useful methodological "tips" on how to actually write a script. According to Akrich (1992), we have to go back and forth between the represented user and the real user, between the way the world is inscribed in the object and the way the world is described by the object displacement. According to Latour (1992), we describe a script

by replacing [the prescriptions encoded in the mechanism] by strings of sentences (often in the imperative) that are uttered (silently and continuously) by the mechanisms for the benefit of those who are mechanized: do this, do that, behave this way, don’t go that way, you may do so, be allowed to go there. (p. 157)

In our paper, these methodological tips have already been used so far to describe the prologue and the intermezzos and will be used further in the discussion section.

\section{The family as a gathering around a thing}

Now, instead of the terms order (Schatzki, 2002) and network (Latour \& Weibel, 2005) to indicate the complex relationship among entities - terms which have a specific ontological meaning and therefore carry the risk to narrow our explorative view - we prefer to see the family as a gathering of some sort.

Etymologically, in Dutch "familie" (gezin) derives from "ghesinde", which meant a group of people undertaking a journey. A "ghesinde” was composed of people related to one another by kinship, allegiance, servitude, and (financial) dependence. More specifically, family referred to a gathering of people who (figuratively and literally) moved in the same direction. Connected to this, we seek to study what kind of gathering the contemporary family is. Our choice to treat family as a gathering is not solely based on Dutch etymology, but it is also based on Heidegger's (1951/1975) broad description of a "thing”: "The Old High German word thing means a gathering, and specifically a gathering to deliberate on a matter under discussion, a contested matter” (p. 174). A thing is never merely a thing, for it gathers in such a way - in its own way - that something comes into existence only by virtue of the thing. The line of thought inspired by Heidegger inaugurates a way towards thinking about "things" as a gathering where we, as humans, no longer take center stage. Human beings are entities, possibly the most important entities, but not the sole entities, of a gathering. In addition to this, perhaps the family is not only a gathering in itself, but a family is sometimes gathered or shows itself around some-thing.

\section{Synthesis}

As seen above, within contemporary perspectives one of the presupposition is that only persons can constitute "family". What happens in a family, what "makes" a family, can therefore be easily bracketed off from materiality. Our contribution, however, is grounded in a more "realist" attitude in the sense that we argue that things co-constitute a persistent 
foundation for some-thing to exist as a family. The socio-material stance places (what we ordinarily think of as) family members not above things but among things. As said, we therefore do not start from seeing "family" as a more or less fixed or stable entity, but instead we want to propose to look at the concrete ways in which members of a family (understood now in a human and non-human sense) endlessly reshape and make our family into a family. We wish to propose seeing the family as an arrangement of human and non-human elements, whereby this family is gathered or shows itself around some-thing or some-one. We use the notion of script to discursively show this gathering, that is, to bring out this gathering in words.

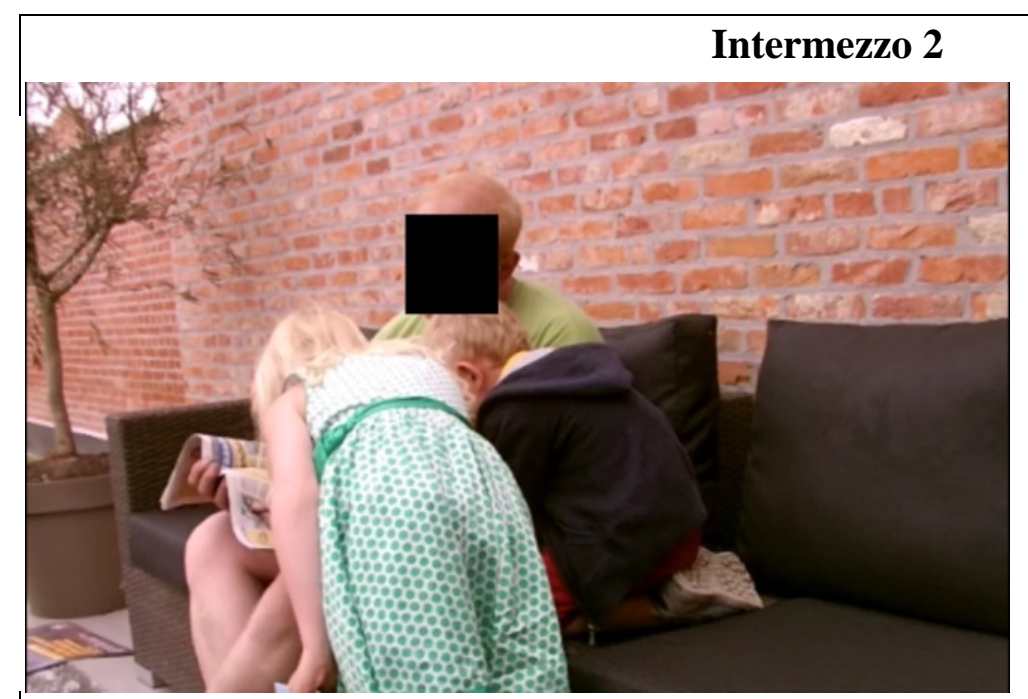

Figure 3. The newspaper and the car crash.

\section{[Script]}

Read me if you want to know more about the world. Read me if you want to know more about the past 24 hours, because that's what I'm for. I will inform you. Ignore me. Let me be. Later on, use me as a coaster. Protect the kitchen table from grease stains and scratches and use me as a table-mat. I provide a surface on which to place objects with minimal noise. In the afternoon, pick me up and carry me outside. Carry me because I don't weigh much. Look and discuss a colorful picture of a car crash. Point at me when you do so.

\section{[Researcher's considerations]}

After a long day at work, the father sinks down in his favorite sofa in the garden. His oldest daughter and his son are close by. Near the father, the boy is sitting on his knees while the girl is standing on her feet. The father is holding the newspaper in his hands. The pages are open. An advertising brochure, which was well hidden between the pages, now lies on the table.

The father bends his head slightly to the left, the index finger of his left hand pointing to a picture. Although it is difficult to see on the photograph, the image is that of a car crash. More specifically, it shows an accident with a racecar. All three of them are looking at the photo. The daughter and the son are leaning forward so they can have a closer look at what happened with the racecar. The girl holds a storybook in her left hand, which is closed and is dangling between her fingers. Just a few seconds ago, she was absorbed by the adventures of a teddy bear, but her attention shifted to the colorful page of the newspaper. At last, the 
newspaper "won" and is being used for what it's made for: giving the reader information. Still, "reading" may be overstating what is happening here. At the moment, the father and his children aren't actually reading the newspaper (and, as said, the boy cannot yet read), they are merely looking at a picture. A battle may almost be won, but the war is still in doubt.

\section{Methodology}

In June 2013, we conducted a broad ethnographic pilot study seeking to register and to describe different kinds of gatherings in the family. On the basis of this pilot study we will now describe one day in the life of a thing and the particular way (this) "family" comes into existence by focusing on that thing. In what follows, we describe how we went about doing this.

In general, when in everyday language the word family pops up there is still a strong tendency to think of the "traditional" nuclear family of two adults and their dependent children. The traditional image of the family retains much of its ideological power, and it was mostly for that reason that we chose to work exclusively with families of the traditional type ${ }^{1}$. Therefore, our cases encompassed a father and mother living together with their biological children. We are aware of the fact that this in fact represents the institution family in a traditional sense, and that this may actually introduce a bias into our research. This is why, in further research, we also want to include other "family types".

In this particular family, we videotaped two slots of a period of time within which most of the family members (in an ordinary sense of the word) were at home. We chose to videotape one slot in the morning and one slot in the afternoon. The researcher accompanied each (human) family member for a minimum of 15 minutes. The method allowed the researcher to videotape "family" not only when mother, father, and their children were together in a room, but also when each of them was busy on his or her own. Hence, it helped us to get a better understanding of "family making" in the context of the home. We were not interested in their point of view about the events having taken place or in the reasons behind their actions. We were interested in the activities they undertook, the things they used or encountered on their path, and the way they were gathered around these things.

The participating family consisted of a mother (age 29), a father (age 31) and three children: two girls (age 7 and 5) and a young boy (age 3). In close consultation with the parents two "research days" were chosen: a try-out and the "actual” research day. The latter was a school day. When the researcher started videotaping (7:00 a.m.), the father had already left the house, gone to work. The researcher videotaped the mother waking up the children, how the family members "prepared" themselves in front of the bathroom mirrors, how the children had breakfast, what they did after breakfast, and how they went to school. The researcher stopped filming at the school gate (8.30 a.m.). Videotaping started again in the

\footnotetext{
${ }^{1}$ The sample consisted of six families; all families were drawn from one area of East-Flanders (Belgium). The general aim of the research was to register and to describe in detail each family in practice. Hence, a fairly small number of families were included. Three methods of inquiry were conducted: (a) videotaping (e.g., Aarsand \& Forsberg, 2010) two slots of a period of time (family A - family B); (b) following one child at the time (e.g., Kusenbach, 2003) (family C - family D); and (c) interviewing each family member about his or her day (family E - family F). It was also an objective to see which methods "work" in grasping family as a "continuous making”. Given the specific aim of this contribution, we will not go deeper into the ethnographic literature itself.
} 
afternoon (16.30 p.m.). While the mother went to the store, the father looked after the children. After about 30 minutes, the father received a phone call and had to leave again. In the meantime, the mother had returned. Together with the children, she took a shower and they pulled on some warm clothes. At that moment, the researcher stayed in the living room and took some field notes. After having had a shower, the children watched television, painted a drawing, and asked for some sweets while the mother prepared dinner. The researcher stopped videotaping at 18.30 p.m.

As for to the presentation of our results, we hope it has become clear by now that we have woven these throughout the contribution (prologue, intermezzos, and epilogue) in order to emphasize the interactive relationships between the object of this particular investigation and other entities. To be precise, our research did not start with the notion to intentionally follow "just" a newspaper. Instead, while analyzing the data, the newspaper suddenly caught our attention as a "thing" that somehow found its way in a lot of footage. We analyzed the data by watching the footage over and over until, to use the words of the Belgian film director Luc Dardenne, "we lose the company of ourselves together with our typical alertness" (as cited in Masschelein, 2010, p. 8, our own translation).

We spent days going over the material until we reached a point where we "lost" ourselves as researchers in our research. We got so tired that we no longer (re)searched but simply watched. In a way, the tiredness enabled us to be more present, to be more open and susceptible for the things that took place before the camera. It was not our intention to focus on one particular object, but while watching the videotapes it became clear that the newspaper took part in the making of this family. We chose to present the results as a mosaic of individually framed fragments, but these still frames are nevertheless connected to one another in a chronological chain of events that - accompanied by an extensive description of the happening - can be read as the life of the newspaper. The prologue, intermezzos, and epilogue are fragments of the "marriage" between a newspaper and a family, that is, the way this document attracted and repelled different family members.

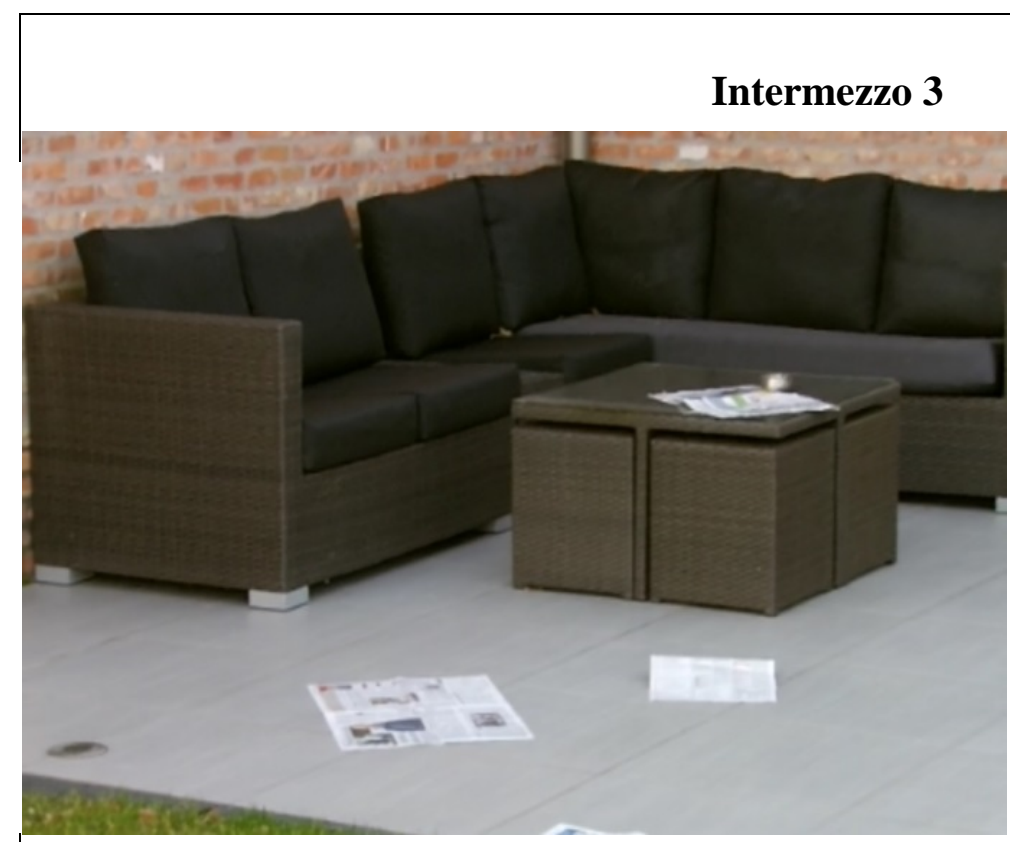

Figure 4. The newspaper as a plaything. 
[Script]

Read me if you want to know more about the world. Read me if you want to know more about the past 24 hours, because that's what I'm for. I will inform you. Ignore me. Let me be. Later on, use me as a coaster. Protect the kitchen table from grease stains and scratches and use me as a table-mat. I provide a surface on which to place objects with minimal noise. In the afternoon, pick me up and carry me outside. Carry me because I don't weigh much. Read me while enjoying the sun. Look and discuss a colorful picture of a car crash. Point at me when you do. Afterwards, leave me outside. Blow parts of me away. Drop me down on tiles and grass. Tear me apart.

[Researcher's considerations]

Time flies. So does a newspaper when left outside. The father is long gone, back on the road, on his way to a new client. He left in a hurry and forgot to take the newspaper inside, leaving it helpless and exposed to the elements of nature. Also the children are nowhere to be seen. The mother came to collect them and they are taking a shower.

A handful of pages are scattered around, lying on the tiles and the grass. Other pages are still lying on the table, "using" the protection of the walls and sofa to withstand the blowing wind. For a few minutes the newspaper is a plaything of nature. Some pages will be irretrievably lost, others will be wrinkled or slightly torn.

\section{Discussion}

As mentioned above, we will come back to the three sections outlined previously, but now specifically focus on the newspaper and the way it has been gathering this family. The three sections act as essential and interconnecting "building blocks" for explaining what a contemporary answer to the question what is family might entail. First, we will (re)turn to the thing itself, the newspaper, as a relational object that throughout the day leaves traces of its doings and that at the same time is in a constant state of being eroded. Second, we will discuss the method of "scripting" as a way to make the newspaper talk, that is, to produce de-scriptions of what the document makes "others" (humans and non-humans) do. Third, we will focus on the way the newspaper is active in gathering the family members.

\section{The turn to a thing: the newspaper}

The newspaper is first and foremost a consumption good, that is, a product that we purchase to receive information (or to satisfy our need for information), but perhaps we can also say something about the newspaper as an (crucial) element in the study of this family. To be precise, we do not conceive of the newspaper as a source or intake to say something about the morality or the meaning-making of the family (as a family), but instead we want to emphasize the newspaper as a constituent of this particular family.

But what does this everyday dealing with the newspaper consist of? As a starting point, we do not consider (the newspaper and) people as autonomous subjects who consciously choose to interact. Family members are not separated from the surrounding area of objects. In line with Schatzki (2002) we maintain that human agency is primary, but this agency is always carried out within a material world. We, human begins endowed with 
agency, are immediately engaged and entangled with things. In a way, we are the things that surround us. Therefore, we are not autonomous selves, but "relational selves" (Gergen, 2009). And if humans are a web of relations, perhaps so are everyday non-human things such as a newspaper. As the results show, throughout the day, the newspaper as a relational thing leaves traces of its doings - traces which prompt us to say: The things on the breakfast table are arranged in that specific order because of the newspaper; the children's book lies a little bit softer on the table because of the newspaper; the children gain more insight in what a car accident might entail because of the newspaper; we are aware that the wind blows because of the newspaper. Of course, the newspaper is not the most determining factor here, but nevertheless the arrangements listed here partly come into existence by virtue of the newspaper. In sum, not only the sheets of paper as such, also all the traces are an integral part of what a newspaper is.

Moreover, if we understand the newspaper as an intersecting node where human and non-human elements meet, we can say something about the specific mode of interacting. Between the prologue and the epilogue, the newspaper disintegrates into smaller parts. In the morning, the newspaper was complete, but throughout the day pages and brochures are removed, transported, and deposited in other locations. This process is as much natural (e.g., the blowing of the wind) as human (e.g., the drawing of the child). After entering the house, the newspaper is in an almost constant state of being eroded. The newspaper's life is fundamentally marked by a process of erosion, that is, by a process through which (the readability of) the newspaper is worn away by the actions of books, children, wind, and so on.

\section{The script of the newspaper}

Akrich (1992) and Latour (1992) developed script-ing as a specific methodology to make things talk, that is, to offer descriptions of things and of what they make others do. The "words" of objects are therefore equated with what they make us do and not do. Scripting thus implies that we "find" the words of the object, that we become aware of the own articulations of things and try to translate these into language. The first sentences of the prologue are carefully chosen ${ }^{2}$ as the script of the (or possibly any?) newspaper: a few short sentences phrased in the imperative mood that are (silently) uttered by the newspaper to whomever crosses its path. A clear prescription on how to use it. And it works. Throughout the day, the newspaper is read (by the father, the mother, but also by the older daughter who tries to read a title of an article upside down when sitting at the breakfast table). If we go back and forth between the design(er) and the user (cf. Akrich, 1992), we can also point out another issue. The continuous collision between the artifact and other entities (mainly people) is transforming the script throughout the day. We argue that the initial script still exists, (i.e., read me if you want to know more ...), but that throughout the day the script or the scenario expands because different "actors" improvise upon or around it (e.g., the child that is painting, the wind that is "playing"). Hence, we want to emphasize script-ing as relational, that is, script-ing is about doing - the interactive relationship between entities - and not so much about having a linear view on how to behave when using the object. The newspaper can (still) be read, but as shown throughout the different intermezzos, the script is dynamically and

\footnotetext{
${ }^{2}$ Writing about the interactive relationship between an object and people, as well as trying to depict the tacit "utterances" of an object, is obviously a task inflicted with its contradictions and problems. How can the implicit be expressed and still be considered tacit? Indeed, "script'-ing” necessarily involves transformations and abstractions. While focusing on the newspaper, there is the risk of losing the "big picture". Nevertheless, we are convinced that material "things"' can be grasped in text.
} 
relationally "rewritten", extended to activities beyond its readability: read me if you want to know more, place a children's book on me, pick me up and carry me outside (and back inside), point at me with your index finger, talk about me with your children, blow me away, drawn on me, and so on. These are not hidden options or possibilities - they were not present from the beginning, ready to be discovered. Instead, the script is "written" in time. Like the depth of a scenario unfolds during a play, what belongs to a script becomes clear in time. While the newspaper slowly erodes (falls apart), the script seems to become more apparent. The interactive relationship between the newspaper and "others" can be captured in a script and this text could be used by a director or performer to play the life of this newspaper in this family. In a way, until the newspaper is finally pulverized in the garbage truck, we cannot truly do justice to its script as a description of its "intimate” relationship with this family.

\section{The family as a gathering around the newspaper}

A "thing” in the sense of Heidegger (1951/1975) refers to a network of relations or an assemblage. It has the potential to gather people around itself. In other words, some-thing starts to (be of) interest.

At first, it seems we are not dealing with a "gathering" at all. The prologue clearly shows that the newspaper, even when taking up a lot of table space, fails to generate interest. We argue, however, that the newspaper does in fact gather (human) family members around itself (as is clearly seen in the picture of the prologue), but, granted, the members are not interested in the newspaper as such. To be precise, the newspaper constitutes a gathering of indifferent people, that is, (human) members who chose to ignore the newspaper or simply used it as a place-mat. Nevertheless, the family members' doings are influenced by the way the newspaper is lying there, by the place it is occupying. What would the scene look like without the newspaper? Would the milk bottle, the cornflake bowls, or the spoons then be using the "vacant space"? Perhaps the children would be sitting in a different formation. We argue that the newspaper, even if the (human) family members are not aware of it, is there and that its presence is making things (im)possible. Intermezzo 2 is giving us a glimpse of another part of the story. By showing a piece of newspaper (or allowing the children to have a look), the father is making cars (crashes)/information visible, and as a result of this is shifting his children's attention to the racecar. They then start learning something about the wider world. At the same time, the newspaper stops being a pure thing for "daddy" and turns into something that is of interest to a group of people. The newspaper has the power (as is literally shown in the picture in intermezzo 2) to gather the family members as a group of people who are (more) interested and involved (than before).

Throughout the day, the newspaper is a "thing" that gathers people, but not every gathering consists of interested people. Intermezzo 3 shows that the newspaper lost, at least temporarily, its ability to generate attention. The father, the mother, and the children left the scene and the newspaper is ripped apart by the wind. Nobody is around, nobody seems to care. Of course, after a while the newspaper makes the (human) family members care because most of its pages are picked up by one of the daughters and the newspaper is put back together to the maximum possible extent. Even the disintegration of the newspaper brings something positive if we look at the next intermezzo (4). After intermezzo 3, the newspaper is no longer (literally and figuratively) "whole". The erosion of the object affects the re-writing of the script which here means that after the "intervention" of the wind, a piece of the newspaper can be more easily transformed/used into drawing paper. The newspaper, wrinkled and torn, lends itself better to this new application. Once again, we have a gathering with 
interested people, although the children are no longer interested in the content of the newspaper but in the white spaces the newspaper offers. But even this is temporary. After a while (the epilogue), the mother asks her oldest daughter to put the newspaper (at least, what is left of it) in the magazine rack. At that moment, the newspaper gathers the family as a thing which has a "right" place and it needs the mother's command and her daughter's moving body to get there, to a place where the newspaper can (be put to) rest after a day of assembling and collecting people.

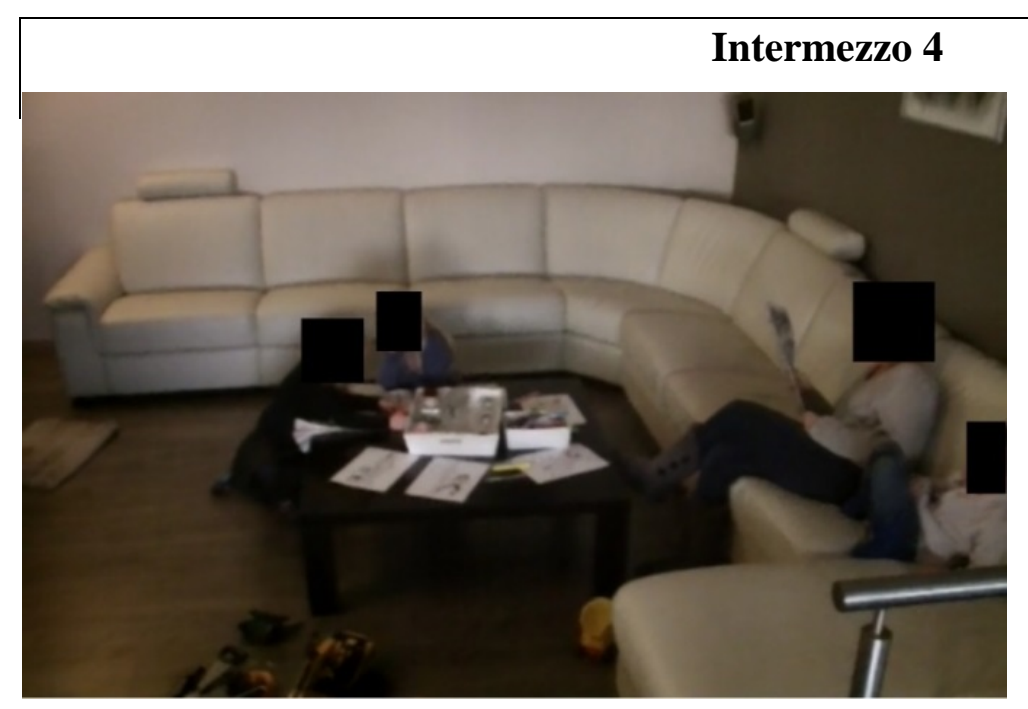

Figure 5. The newspaper as drawing paper.

\section{[Script]}

Read me if you want to know more about the world. Read me if you want to know more about the past 24 hours, because that's what I'm for. I will inform you. Ignore me. Let me be. Later on, use me as a coaster. Protect the kitchen table from grease stains and scratches and use me as a table-mat. I provide a surface on which to place objects with minimal noise. In the afternoon, pick me up and carry me outside. Carry me because I don't weigh much. Read me while enjoying the sun. Look and discuss a colorful picture of a car crash. Point at me when you do. Afterwards, leave me outside. Blow parts of me away. Drop me down on tiles and grass. Tear me apart. In the evening, pick me up and carry me inside. Carry me because I don't weigh much. Read a part of me while sitting in a couch. Use another part of me as drawing paper. Look how the drawing is being made.

[Researcher's considerations]

After a refreshing shower, the mother and her three children are in the "lounge": a seating area situated a bit lower than the dining room. The mother is sitting on a white couch and holds a piece of newspaper in her hands (a piece that survived the "storm"). Her son, who is sitting next to her, watches television (the TV set is just outside the image). To be precise, the boy is the only one watching television. The other three people in the area are preoccupied by something else (i.e., reading and drawing). The two daughters sit on the parquet flooring. There is a small table. Various markers and crayons are in a small box on top of the table. Some toy trucks and cars are lying on the ground. Indeed, there are many "child-oriented" products within reach. But what is going on in this picture? For a moment, one child ignores 
the printed drawings on the table and instead uses the newspaper as drawing paper while the other child watches closely - which means that part of the newspaper is being read, while another part of it "competes" with "other" drawing papers.

\section{Conclusion}

In this article we wanted to propose another way of approaching the "making” of a family, namely how "family" is on a daily basis "put together" and the concrete things involved in this "continuous making of". In this contribution, we showed how a particular family is made or can be seen when (human and non-human) family members are being gathered around the "life" of a newspaper. It would be an overstatement to say that the newspaper plays a central role in the "making" of this family, but nevertheless it becomes clear that the newspaper is intrinsically and indispensably involved in enabling (inter)actions of many different kinds.

First, we focused on the newspaper itself. We argue that the newspaper can be seen as an intersecting node which leaves traces of its doing and that these traces are as much a part of its being (its thingness) as the bundle of paper. Also, the relation of the newspaper with the family is a relation based on erosion, that is, a relation by which the readability of the newspaper is worn away by the actions of humans and non-humans. Second, we used scripting as a specific descriptive method to bring the newspaper into play. We argue that the script of a thing can expand and that this expansion is related to the act of scripting, that is, a dynamical and relational doing through time where all sort of entities are involved. Third, we focused on the family as a gathering around the newspaper. We argue that the newspaper gathers people, even if (human) family members do not seem to be interested. In other words, the newspaper makes possible that people meet each other, but the assembly of persons is not always consciously aware that they are being gathered.

In sum, what "makes" a family from our socio-material perspective are our everyday gatherings around and with mundane things such as a newspaper. This is not to say, of course, that things are the only vital component of "family". We just wanted to put into words the everyday experience that "family" is more than adults and children, that the things that surround us are, in a certain way, also members of our family. These "family members" (dis)appear and make us (not) do things. Throughout the analysis it became clear that "family making” is, in a certain way, "distributed" between (non-human) family members. Of course, there are 50 shades of grey between full membership and sheer co-existence but "things" are out there, we fill our houses with them, so perhaps it becomes time to acknowledge that we are not only using them while living, but that on many occasions (co-)existence becomes possible because of them. We are not above things, but among them. Or to describe it more metaphorically, family is perhaps a continuous re-membering. Various members regroup and in doing so they form "family". 


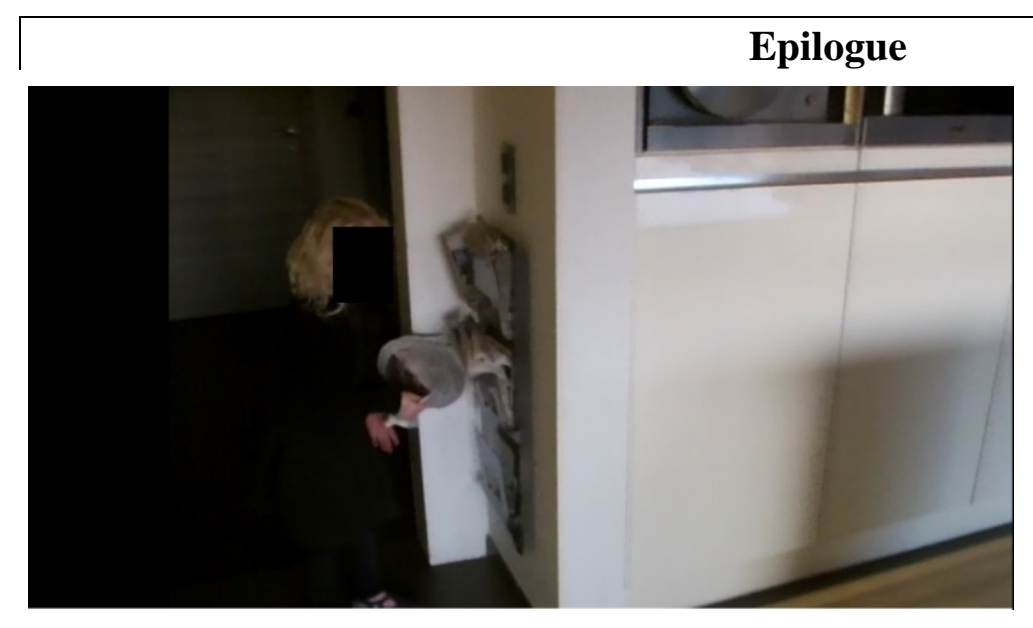

Figure 6. The newspaper in the magazine rack.

\section{[Script]}

Read me if you want to know more about the world. Read me if you want to know more about the past 24 hours, because that's what I'm for. I will inform you. Ignore me. Let me be. Later on, use me as a coaster. Protect the kitchen table from grease stains and scratches and use me as a table-mat. I provide a surface on which to place objects with minimal noise. In the afternoon, pick me up and carry me outside. Carry me because I don't weigh much. Read me while enjoying the sun. Look and discuss a colorful picture of a car crash. Point at me when you do. Afterwards, leave me outside. Blow parts of me away. Drop me down on tiles and grass. Tear me apart. In the evening, pick me up and carry me inside. Carry me because I don't weigh much. Read a part of me while sitting in a couch. Use another part of me as drawing paper. Look how the drawing is being made. At the end of the day, thrown a part of me in the bin. Put another part of me in the magazine rack. Ignore me. Let me be. Forget about me.

\section{[Researcher's considerations]}

It is almost dinnertime, and the mother asks her children to clean up the "lounge". The mother asks her oldest daughter to put the newspaper in the magazine rack. To be precise, she asks the daughter to put away the part the mother read. The piece of newspaper that was used as drawing paper is thrown in the bin. The rack hangs on the left side of a kitchen closet and consists of three shelves. Other ("old") newspapers are already in place, waiting for their weary comrade. The girl puts the newspaper on the second shelf where it will remain during the night, losing its relevance as the bringer of new facts. 


\section{References}

Aarsand, P., \& Forsberg, L. (2010). Producing children's corporeal privacy: Ethnographic video recording as material-discursive practice. Qualitative research, 10(2), 249-268. http://dx.doi.org/10.1177/1468794109356744

Akrich, M. (1992). The De-scription of technical objects. In W. Bijker \& J. Law (Eds.), Shaping technology, building society: Studies in sociotechnical change (pp. 205-224). Cambridge, MA: MIT Press.

Bernardes, J. (1999). We must not define "the family". Marriage and Family Review, 28, 2144. http://dx.doi.org/10.1300/j002v28n03_03

Gergen, K. J. (2009). Relational being: Beyond self and community. New York: Oxford University Press.

Heidegger, M. (1975). The thing. In M. Heidegger (Ed.), Poetry, language, thought (A. Hofstadter, Trans.) (pp. 161-184). New York, London: Harper Colophon books. (Original work published 1951)

Holtzman, M. (2008). Defining family: Young adults' perceptions of the parent-child bond. Journal of Family Communication, 8(3), 167-185. http://dx.doi.org/10.1080/15267430701856887

Koerner, A. F., \& Fitzpatrick, M. A. (2004). Communication in intact families. In A. L. Vangelisti (Ed.), Handbook of family communication (pp. 177-195). Mahwah, NJ: Lawrence Erlbaum. http://dx.doi.org/10.4324/9780203848166.ch8

Kusenbach, M. (2003). Street phenomenology: The go-along as ethnographic research tool. Ethnography, 4(3), 455-485. http://dx.doi.org/10.1177/146613810343007

Laidlaw, L. (2006). Learning to "do family" differently: Towards more complex notions of family, culture, and schooling. Journal of the Canadian Associations for Curriculum Studies, 4(2), 41-54.

Latour, B. (1992). Where are the missing masses? Sociology of a few mundane artifacts. In W. Bijker \& J. Law (Eds.), Shaping technology, building society: Studies in sociotechnical change (pp. 225-258). Cambridge, MA: MIT Press.

Latour, B. (2005). Reassembling the social. New York: Oxford University Press.

Latour, B., \& Weibel, P. (2005). Making things public: Atmospheres of democracy. Cambridge, MA: MIT Press.

Masschelein, J. (2010). De cinema van de Dardennes als publieke denkoefening. In de bres tussen verleden en toekomst [The cinema of the brothers Dardennes as a public exercise. The gap between past and future]. Oikos: Forum voor Sociaal-Ecologische Verandering [Oikos: Forum for Social-Ecological Change], 55(4), 38-46.

Mol, A. (2002). The body multiple. Ontology in medical practice. Durham, NC/London: Duke University Press. 
International Journal of Child, Youth, and Family Studies (2014): 5(4.2) 722-740

Morgan, D. (1996). Family connections: An introduction to family studies. Cambridge, UK: Polity Press.

Morgan, D. (2011). Rethinking family practices. Basingstoke, UK: Palgrave Macmillan.

Murdock, G. P. (1949). Social structure. New York: The MacMillan Company

Newman, D. M., \& Grauerholz, E. (2002). Sociology of families. Thousand Oaks, CA: Pine Forge Press.

Parsons, T. (1955). The American family: Its relations to personality and the social structure. In T. Parsons \& R. F. Bales (Eds.), Family, socialization and interaction process (pp. 3-33). Glencoe, IL: The Free Press.

Pinch, T. (2010). On making infrastructure visible: putting the non-humans to rights. Cambridge Journal of Economics, 34(1), 77-89. http://dx.doi.org/10.1093/cje/bep044

Segrin, C., \& Flora, J. (2014). Family communication. New York: Routledge.

Schatzki, T. R. (2002). Site of the social: A philosophical account of the constitution of social life and change. University Park, PA: Penn State Press.

Stephens, W. N. (1963). The family in cross-cultural perspective. New York: Holt, Rinehart \& Winston.

Thornton, A., \& Young-DeMarco, L. (2001). Four decades of trends in attitudes toward family issues in the United States: The 1960s through the 1990s. Journal of Marriage and Family, 63(4), 1009-1037.http://dx.doi.org/10.1111/j.1741-3737.2001.01009.x

Verbeek, P. P. (2011). Moralizing technology: Understanding and designing the morality of things. Chicago/London: University of Chicago Press.

Weigel, D. J. (2008). The concept of family: An analysis of lay people's views of family. Journal of Family Issues, 29(11), 1426-1447. http://dx.doi.org/10.1177/0192513x08318488 